\title{
Características clínicas da fase aguda da infecção experimental de felinos pelo vírus da imunodeficiência felina ${ }^{1}$
}

\author{
Marcelo S. Zanutto ${ }^{\star}$, Tilde R. Froes ${ }^{3}$, Adriana L. Teixeira ${ }^{4}$ e Mitika K. Hagiwara ${ }^{5}$
}

\begin{abstract}
Zanutto M.S., Froes T.R., Teixeira A.L. \& Hagiwara M.K. 2011. [Clinical characteristics of the acute phase of feline immunodeficiency virus experimental infection.] Características clínicas da fase aguda da infecção experimental de felinos pelo vírus da imunodeficiência felina. Pesquisa Veterinária Brasileira 31(3):255-260. Departamento de Clínicas Veterinárias, Centro de Ciências Agrárias, Universidade Estadual de Londrina, Rodovia Celso Garcia Cid s/n, Londrina, PR 86051-990, Brazil. E-mail: mzanutto@uel.br
\end{abstract}

As a result of FIV infection of cats, feline immunodeficiency syndrome might be seen in the latter phase of infection. Gengivitis, weight loss, spread enlargement lymph nodes, anemia, chronic renal failure, neurological disturbances, chronic diarrhea, and oportunistic bacterial infections are commonly found. The acute phase of the infection might be unnoticed, making the diagnosis difficult and delaying the adoption of profilatic measures, in order to reduce FIV transmission for other susceptible cats. Aiming to study the clinical characteristics of the acute phase of FIV infection, ten young eight month old cats mixed breed were succesfully inoculated by intravenous route with one $\mathrm{mL}$ of blood obtained from one FIV-B positive cat. The infection was confirmed by ELISA test four and eight weeks p.i and nested-PCR. CBC counting, abdominal ultrasonography and ophtalmologic exams were done weekly, fortnightly and monthly during twelve weeks p.i. Mild tendency to lymphopenia at second week and neutropenia between fifth and seventh weeks p.i., fever in a few cats and lymph nodes, spleen and hepatic enlargements were the main clinical alterations found. The latters became evident starting on fourth week and remained throughout the twelve weeks observation period. Only one cat showed unilateral rigt uveitis. The acute phase of FIV infection elapsed with inespecific clinical manifestations. Lymph node, hepatic and spleen enlargements seen, though, suggest the needs for indication of tests for the diagnosis of FIV infection in all cats presenting those signs, thus allowing early diagnosis of FIV infection and the adoption of prophylatic measures.

INDEX TERMS: Feline, virus, feline immunodeficiency, acute infection, ultrasonography.

RESUMO.- A infecção dos felinos pelo Vírus da Imunodeficiência Felina (FIV) resulta no desenvolvimento da síndrome de imunodeficiência dos felinos. Gengivite, perda

\footnotetext{
${ }^{1}$ Recebido em 11 de maio de 2010.

Aceito para publicação em 19 de setembro de 2010.

2 Departamento de Clínicas Veterinárias, Centro de Ciências Agrárias, Universidade Estadual de Londrina (UEL), Rodovia Celso Garcia Cid s/n, Londrina, PR 86051-990, Brasil. Autor para correspondência: mzanutto@uel.br

${ }^{3}$ Departamento de Medicina Veterinária, Setor de Ciências Agrárias, Universidade Federal do Paraná (UFPR), Rua dos Funcionários 1540, Curitiba, PR 80035-050, Brasil.

${ }^{4}$ Médica Veterinária autônoma, Avenida dos Imaraés 317/43, São Paulo, SP 04085-000.

${ }^{5}$ Departamento de Clínica Médica, Faculdade de Medicina Veterinária e Zootecnia (FMVZ), Universidade de São Paulo (USP), Av. Prof. Dr. Orlando Marques de Paiva 87, São Paulo, SP 05508-900, Brasil.
}

de peso, linfadenomegalia generalizada, anemia, insuficiência renal crônica, complicações neurológicas, diarréia crônica e infecções bacterianas são encontradas frequentemente. A fase aguda da infecção pode ser assintomática, retardando o estabelecimento do diagnóstico e a implantação de medidas profiláticas para restringir o contágio e a transmissão do agente aos felinos suscetíveis. Com a finalidade de estudar as características clínicas da fase aguda da infecção, dez felinos jovens, sem definição racial, com oito meses de idade foram inoculados por via endovenosa com $1 \mathrm{~mL}$ de sangue venoso de um gato portador do FIV subtipo B. A confirmação da infecção foi obtida através de teste sorológico em quatro e oito semanas pós-inoculação (p.i.) e por nested-PCR. Foram realizados hemogramas semanais, exame ultrassonográfico do abdômen quinzenais e exame oftalmológico mensal, durante 
doze semanas p.i. Discreta tendência a linfopenia na segunda semana p.i. e a neutropenia entre a quinta e sétima semana p.i., febre intermitente em alguns gatos, linfadenomegalia e hepato-esplenomegalia entre a quarta e a $12^{\text {a }}$ semana p.i. foram as alterações clínicas observadas. Apenas um gato apresentou uveíte unilateral direita. A fase aguda da infecção transcorreu com alterações clínicas inespecíficas. A linfadenomegalia e a hepato-esplenomegalia observadas no decorrer da infecção, refletindo hiperplasia linfóide, sugerem a necessidade de se realizar o teste sorológico para o FIV, em todos os gatos que se apresentarem com essas alterações, o que permitirá o diagnóstico precoce da infecção e a adoção de medidas profiláticas no sentido de minimizar a propagação da infecção.

TERMOS DE INDEXAÇÃO: Felinos, vírus, imunodeficiência felina, infecção aguda, ultrassonografia.

\section{INTRODUÇÃO}

Desde a descrição inicial da infecção dos felinos por um vírus linfotrópico (vírus da imunodeficiência felina [FIV]) (Pedersen et al. 1987), o mecanismo envolvido no desenvolvimento da imunodeficiência dos felinos vem sendo amplamente estudado, considerando-se principalmente a semelhança entre a infecção dos felinos e a infecção humana pelo Vírus da Imunodeficiência Humana (HIV) (Tompkins \& Tompkins 2008). O FIV encontra-se amplamente disseminado entre a população felina (Reche Jr et al. 1997, Souza et al. 2002, Levy et al. 2006), sendo os gatos de vida livre e os machos adultos e não castrados, os mais afetados, pois a transmissão ocorre principalmente pela mordedura.

O FIV infecta linfócitos T CD4, T CD8, linfócitos B e macrófagos (Dean et al. 1996, Troth et al. 2008), o que resulta na perda lenta e progressiva de linfócitos T CD4, inversão da relação CD4/CD8 e o bloqueio da atividade mitótica linfocitária após estimulação antigênica (Torten et al. 1991). Além do aumento na predisposição a várias doenças infecciosas, a imunossupressão resultante da infecção pelo FIV leva a uma maior predisposição ao desenvolvimento de tumores linfoides (Willis 2000).

A evolução clínica da infecção pelo FIV é em geral longa, de anos (Burkhard et al. 2002, Sellon \& Hartmann 2006), dependendo do grupo viral envolvido. Os vírus do subtipo $A$ apresentam virulência e carga viral baixa (Pedersen et al. 2001), ao passo que os vírus pertencentes ao subtipo $B$ têm maior tropismo por monócitos e macrófagos, o que induz inversão mais rápida da relação CD4/CD8 e, consequentemente, imunodeficiência (Dow et al. 1999, Burkhard et al. 2002). Pedersen et al. (2001) observaram maior virulência dos vírus do subtipo $C$ em comparação aos do subtipo $A, O$ que causa neutropenia e linfopenia mais intensas e carga viral mais alta durante a fase aguda da infecção. A via de inoculação do vírus, além do subtipo e a dose infectante, podem influenciar a magnitude da carga viral e a manifestação clínica no hospedeiro, conforme observado por Burkhard et al. (2002) através da inoculação de gatos com os vírus dos subtipos A e B pela via vaginal e pela via endovenosa.
À semelhança da infecção humana, a infecção pelo FIV pode ser dividida em cinco estágios sequenciais (Sellon \& Hartmann 2006). A fase aguda pode passar despercebida na maioria dos gatos. Alguns gatos infectados apresentam linfadenomegalia transitória, febre, apatia e anorexia por mais de uma semana. Eventualmente pode ocorrer neutropenia (Sparkes et al. 1993, Linenberger et al. 1995), o que predispõe o gato a infecções bacterianas oportunistas, com manifestações clínicas diversas, sendo a mais frequente a gengivite crônica (Beebe et al. 1994, English et al. 1994). Segue-se a isso um período de meses a anos, em que a infecção é assintomática. Linfadenomegalia generalizada, febre, anorexia, perda de peso e alterações comportamentais geralmente ocorrem com a progressão da infecção (Brown et al. 1991, Matsumura et al. 1993, Phillips et al. 1996). Infecções crônicas secundárias ou associadas, causadas por agentes infecciosos comensais ou patogênicos são frequentes. Com a instalação da síndrome de imunodeficiência felina adquirida, associada ou não a infecções secundárias, podem ser observadas desordens neurológicas, oculares ou neoplasias. Uveíte anterior (English et al. 1994, Loesenbeck et al. 1995), conjuntivite crônica (Nasisse et al. 1993) e linfoma ocular (Willis 2000) são algumas alterações oculares que podem ser encontradas em gatos infectados pelo FIV. O diagnóstico da infecção pelo FIV é estabelecido rotineiramente por meio de testes sorológicos, pesquisando-se anticorpos contra o FIV (Rimmelzwaan et al. 1994) e mais recentemente por meio de técnicas de biologia molecular como a nestedPCR (Hohdatsu et al. 1998, Lara et al. 2007).

Devido à variedade de manifestações clínicas, os gatos que apresentem infecções crônicas ou recidivantes, perda de peso, distúrbios digestivos, respiratórios, oftalmológicos ou neurológicos, alterações hematológicas e neoplasias devem ser submetidos aos testes para o diagnóstico da infecção. Entretanto, por causa da ausência de sinais clínicos, ou da existência de sinais clínicos discretos, a fase aguda da infecção viral pode passar despercebida, o que dificulta o estabelecimento precoce do diagnóstico. A ausência ou a variabilidade de sintomas na população felina infectada pode refletir os diferentes subtipos do vírus, como também a variação no subtipo com vírus mais ou menos virulentos, a dose infectante e a resposta imune do hospedeiro. Assim, as características clínicas da fase aguda nos gatos infectados por um subtipo brasileiro do FIV, podem fornecer subsídios para a identificação mais precoce dos indivíduos infectados.

\section{MATERIAL E MÉTODOS}

Vinte gatos (10 machos e 10 fêmeas), sem raça definida, foram mantidos no Centro de Estudos de Doenças de Cães e Gatos do Departamento de Clínica Médica da Faculdade de Medicina Veterinária e Zootecnia da Universidade de São Paulo, a partir de 45 dias de idade, com alimentação à base de ração comercial $^{6}$, imunizados contra rinotraqueíte infecciosa, calicivirose, panleucopenia e clamidiose felinas ${ }^{7}$ e raiva ${ }^{8}$, vermifugados (fenbendazole) com 4, 6, 10 e 14 semanas de idade e 
após semestralmente. Para prevenir infestação por pulgas foi utilizado fipronil ${ }^{9}$ mensalmente. Aos 8 meses de idade, 10 gatos (cinco machos e cinco fêmeas) foram sorteados e constituíram o grupo experimental (Grupo I). Os demais constituíram o grupo controle (Grupo II). Os gatos do Grupo I receberam, por via endovenosa, $1,0 \mathrm{~mL}$ de sangue total imediatamente após a coleta de um gato infectado naturalmente pelo FIV, sintomáti$\mathrm{co}$, reagente ao teste imunoenzimático ${ }^{10}$. A estirpe viral foi classificada como sendo do grupo B por meio da nested-PCR e posterior seqüenciamento da região p17-p24 do gene gag (Lara et al. 2007). Não foi possível quantificar a carga viral do inóculo utilizado.

Após a infecção, todos os gatos passaram por exame clínico diário durante 12 semanas. Amostras de sangue foram colhidas em intervalos semanais, para a realização de hemograma, e os exames ultrassonográficos do abdômen ${ }^{6}$ e oftalmológicos ${ }^{7}$ foram realizados em intervalos de 15 dias e de 30 dias, respectivamente. Inicialmente, o estudo ultrassonográfico era realizado de forma cega, ou seja, o examinador não sabia quais eram os felinos inoculados, sendo que em determinado momento esta diferenciação não foi possível devido às alterações ultrassonográficas encontradas. Considerou-se o fígado de tamanho normal, quando o parênquima encontrava-se adjacente ao diafragma não ultrapassando o arco costal. O tamanho do baço foi estimado subjetiva e quantitativamente, medindo-se a espessura do órgão na região média. Essa mensuração foi realizada no plano de corte longitudinal, traçando-se uma linha reta perpendicular ao eixo transversal pelo calibre eletrônico do apareIho, posicionando o mesmo na superfície ventral e dorsal do órgão, ao nível da cápsula esplênica em sua porção aparentemente mais larga. Os resultados foram expressos em relação aos achados ultrassonográficos encontrados no fígado, vesícula biliar, baço, rins, bexiga, alças intestinais e linfonodos abdominais. A frequência destas alterações foi expressa em termos de porcentagens de acordo com sua ocorrência e comparandose os grupos. As medidas esplênicas e dos linfonodos abdominais (quando aumentados) foram comparados entre os dois grupos pelo teste t-student com intervalo de confiança a $5 \%$, com todos os dados dos diferentes momentos da infecção.

A punção aspirativa do linfonodo pré-escapular ${ }^{8}$ foi realizada em cinco gatos, na oitava semana pós-infecção. A pesquisa de anticorpos anti-FIV ${ }^{9}$ foi realizada antes da infecção experimental e na quarta e oitava semana pós-infecção (p.i.). A presença da infecção foi identificada cinco meses após por meio da técnica de nested-PCR (Hohdatsu et al. 1998).

Os valores leucocitários de neutrófilos e linfócitos absolutos, por não apresentarem distribuição paramétrica, foram transformados em raiz quadrada, aplicando-se a seguir o teste múltiplo de Duncan para a comparação das médias de neutrófilos segmentados e de linfócitos entre as semanas p.i. e o momento prévio à inoculação.

\footnotetext{
${ }^{6}$ Friskies ${ }^{\circ}$, Nestlé Brasil Ltda, Av. Dr. Chucri Zaidan 246, Vila Cordeiro, São Paulo, SP.

7 Eclipse-4®, Fort Dodge Saúde Animal Ltda, R. Luiz Fernando Rodriguez 1701, Campinas, SP.

${ }^{8}$ Rai-Vac $®$, Fort Dodge Saúde Animal Ltda, R. Luiz Fernando Rodriguez 1701, Campinas, SP.

${ }^{9}$ Frontline®, Merial Saúde Animal Ltda, Av. Dr. Carlos Grimaldi 1701, 4º andar, Jd. Conceição, Campinas, SP.

10 Snap-Combo® FIV-FeLV, IDEXX Laboratories, One IDEXX Drive, Westbrook, Maine, 04092, USA.
}

\section{RESULTADOS}

A infecção dos felinos pelo FIV foi comprovada pela soroconversão de todos os gatos inoculados, quatro e oito semanas p.i. e confirmada pela amplificação de material genético específico do provírus integrado em linfócitos periféricos dos felinos do Grupo I (Fig.1). Os felinos do Grupo II permaneceram saudáveis, não reagentes ao teste sorológico e à amplificação de material genético do FIV a partir do sangue periférico.

No Grupo I não foram observadas alterações no apetite, perda de peso, distúrbios digestivos, respiratórios ou neurológicos. Entretanto, picos febris isolados ou ocasionais $\left(39,6-40,4^{\circ} \mathrm{C}\right)$ foram observados na maioria dos gatos inoculados $(90 \%)$ a partir da terceira semana p.i. A alteração mais consistente, observada a partir da segunda semana p.i., foi o aumento progressivo dos linfonodos periféricos, inicialmente mais evidente em linfonodos da região cervical. Uveíte anterior foi detectada na quinta semana p.i. em um dos gatos infectados, que respondeu à corticoterapia tópica com resolução completa em seis dias.

As principais alterações ultrassonográficas visualizadas no Grupo I foram: esplenomegalia, seguidos por linfadenomegalia, hepatomegalia e discreta alteração na vesícula biliar. No fígado, diminuição difusa da ecogenicidade foi visualizada em $40 \%$ dos gatos, sendo essas alterações detectadas a partir da oitava semana p.i. Cerca de $15 \%$ dos gatos apresentaram também alteração em vesícula biliar como: bile

\section{$\begin{array}{lllllll}1 & 2 & 3 & 4 & 5 & 6 & 7\end{array}$}

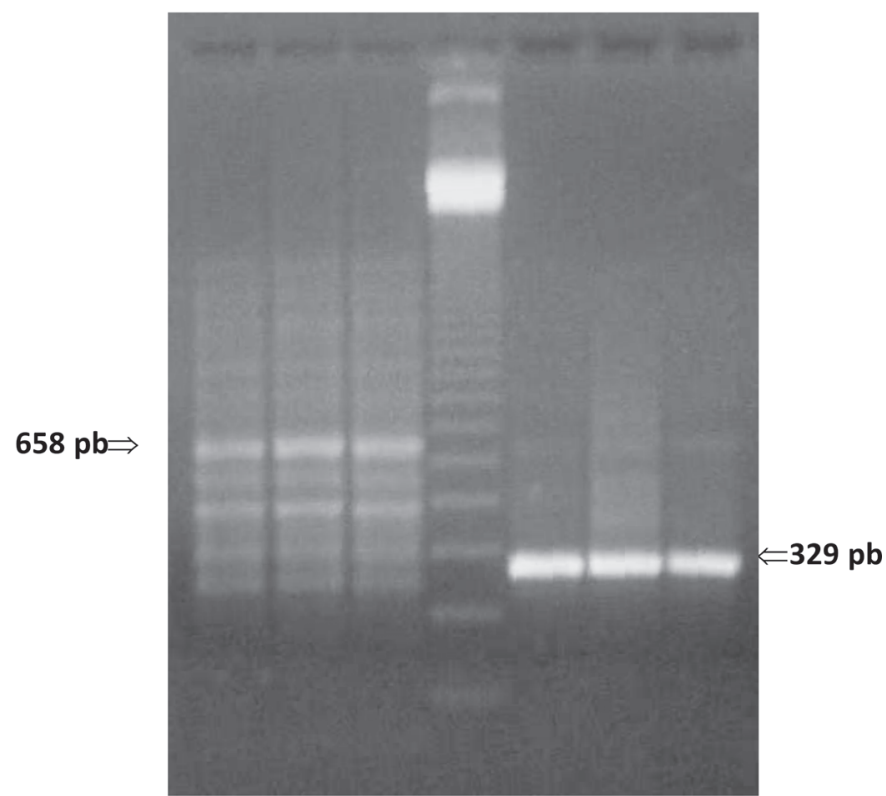

Fig.1. Visualização de material genético amplificado específico do VIF pela reação de PCR e PCR-Nested. Nas colunas 1,2 e 3 são observadas bandas com material genético amplificado da reação de PCR (658 pares de base - pb), na coluna 4 o marcador de $123 \mathrm{pb}$, e nas colunas 5,6 e 7 bandas com material genético amplificado da reação de PCR-Nested (329 pb). São Paulo, 2004. 

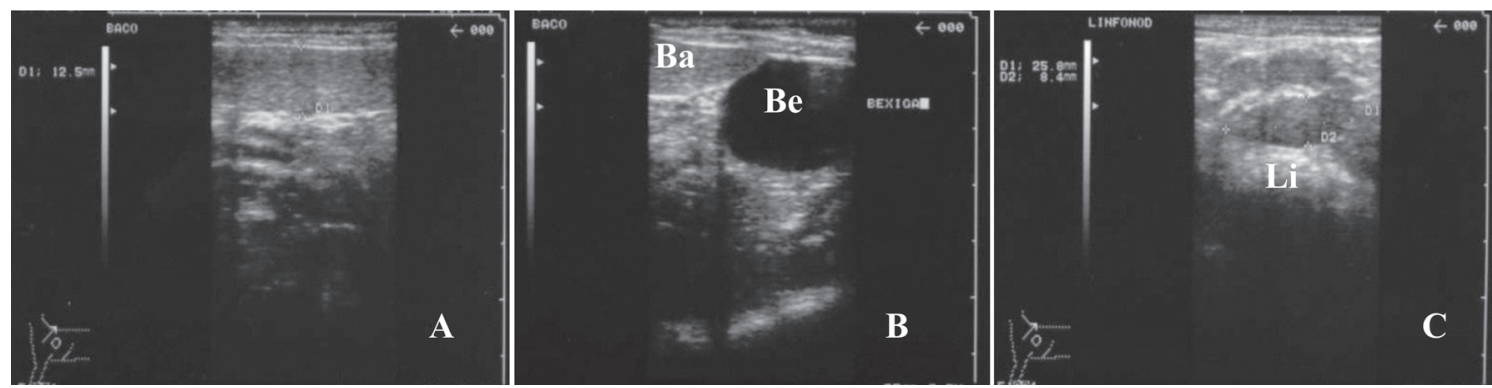

$\mathrm{Li}=$ Linfonodo; $\mathrm{Ba}=\mathrm{Baço} ; \mathrm{Be}=$ Bexiga.

Fig.2. Ultrassons abdominais de felino inoculado experimentalmente com o VIF com seis semanas pósinfecção. (A) Linfonodomegalia mesentérica. (B) Relação anatômica do baço aumentado de volume e vesícula urinária. (C) Esplenomegalia. São Paulo, 2004.

\begin{tabular}{|c|c|c|}
\hline Tempo (semanas p.i.) & Grupo I & Grupo II \\
\hline Pré- inoculação & $6,94 \pm 1,88$ & $7,01 \pm 1,09$ \\
\hline 2 & $8,11 \pm 2,45$ & $8,29 \pm 1,34$ \\
\hline 4 & $7,93 \pm 2,00$ & $7,51 \pm 1,39$ \\
\hline 6 & $9,76 \pm 1,55$ & $8,11 \pm 1,41$ \\
\hline 8 & $10,31 \pm 1,30$ & $8,32 \pm 1,03$ \\
\hline 10 & $11,02 \pm 1,31$ & $9,30 \pm 1,44$ \\
\hline 12 & $11,84 \pm 1,30$ & $8,98 \pm 1,55$ \\
\hline
\end{tabular}

concentrada e parede espessa e levemente irregular. Discreta dilatação de ducto cístico e vias biliares intra-hepáticas e colédoco também foram visualizadas em $5 \%$ dos gatos. No baço, ecogenicidade difusamente heterogênea (com múltiplos nódulos hipoecóicos, de 0,3-1,0cm de diâmetro) e esplenomegalia subjetiva e quantitativa (Fig.2A,B), foram detectadas a partir da sexta semana p.i. até o final do experimento. $\mathrm{Na}$ análise do tamanho do baço a diferença entre os grupos começou a ser significante a partir da sexta semana, na oitava semana a diferença foi considerada muito significativa pelo teste, persistindo até o final do estudo (Quadro 1). Observou-se também linfadenomegalia abdominal generalizada. Os linfonodos visibilizados foram: gástricos, peri-portais, mesentéricos e raramente os ilíacos. O tamanho dos linfonodos mesentéricos variou de 11,4 a $34,5 \mathrm{~mm}$, média de 15,9 $95,8 \mathrm{~mm}$, sendo que o número dos linfonodos identificados era aproximadamente três por exame. Esses linfonodos apresentaram-se sólidos e hipoecóicos (Fig.2C). Essa anormalidade também foi detectada em torno da sexta a oitava semana p.i., persistindo até a última análise. No Grupo II (controle), em um número pequeno de gatos (20\%) foi observada esplenomegalia leve, linfadenomegalia mesentérica discreta não sustentada e esporádica em todo o período do estudo. O tamanho dos linfonodos mesentéricos variou de 6,5 a $18,4 \mathrm{~mm}$, com média de $13,5 \pm 3,7 \mathrm{~mm}$, novamente constatou-se diferença muito significante entre os dois grupos. Não foi visualizada nenhuma alteração ultrassonográfica em bexiga, rins e alças intestinais nos grupos.

Hiperplasia linfoide foi observada na citologia aspirativa de linfonodo pré-escapular direito de cinco dos gatos infec-

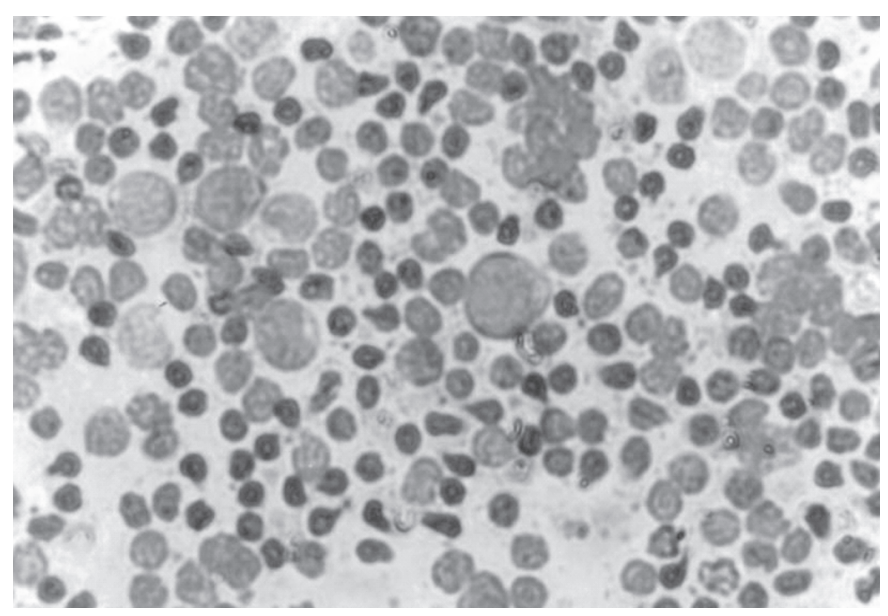

Fig.3. Aspirado por agulha fina de linfonodo pré-escapular direito de felino inoculado experimentalmente com o FIV com seis semanas de evolução. Coloração: Rosenfeld. Aumento 40x. São Paulo, 2004.

tados (Fig.3). As alterações hematológicas foram mínimas durante a fase de instalação da infecção. Não houve alteração do eritrograma entre os grupos. Foi observada tendência a linfopenia na segunda semana p.i. e neutropenia entre a quinta e a sétima semanas p.i (Quadro 2).

\section{DISCUSSÃO}

A infecção de gatos suscetíveis pelo FIV brasileiro do subtipo $B$ não resultou no desenvolvimento de sintomas graves na fase aguda, como os que haviam sido relatados por English et al. (1994) e Diehl et al. (1995). Apesar da discreta tendência a neutropenia, evidenciada entre a quinta e sétima semana p.i., não foram observados quaisquer sintomas de infecção secundária ou oportunista, como as relatadas por Moraillon et al. (1992) e Beebe et al. (1994), provavelmente em função da mínima alteração quantitativa dos neutrófilos ou pelo tempo de observação do experimento. A neutropenia é relatada nas infecções dos felinos pelo FIV (Linenberger et al. 1995, Pedersen et al. 2001) o que propicia o aparecimento de sintomas como diarreia e gengivite devido às infecções oportunistas. A tendência a linfopenia que ocorreu ao redor da segunda semana p.i. e os picos febris evi- 
Quadro 2. Valores absolutos de neutrófilos segmentados e linfócitos sanguíneos semanais de 10 gatos inoculados experimentalmente com o vírus da imunodeficiência felina durante 12 semanas. São Paulo, 2004

\begin{tabular}{|c|c|c|c|c|c|c|c|c|c|c|c|c|c|}
\hline \multirow[t]{2}{*}{ Variável } & \multicolumn{13}{|c|}{ Semanas pós-inoculação } \\
\hline & 0 & 1 & 2 & 3 & 4 & 5 & 6 & 7 & 8 & 9 & 10 & 11 & 12 \\
\hline Neutrófilos & $\begin{array}{l}7517 \pm \\
3157^{a}\end{array}$ & $\begin{array}{c}6587 \pm \\
2892^{a b}\end{array}$ & $\begin{array}{c}6510 \pm \\
4758^{a b}\end{array}$ & $\begin{array}{l}7594 \pm \\
4418^{a}\end{array}$ & $\begin{array}{c}5760 \pm \\
2979^{a b}\end{array}$ & $\begin{array}{l}4087 \pm \\
2136^{b}\end{array}$ & $\begin{array}{l}3945 \pm \\
2352^{b}\end{array}$ & $\begin{array}{l}4206 \pm \\
1872^{b}\end{array}$ & $\begin{array}{c}4577 \pm \\
2761^{a b}\end{array}$ & $\begin{array}{c}5610 \pm \\
3177^{a b}\end{array}$ & $\begin{array}{c}4961 \pm \\
2615^{a b}\end{array}$ & $\begin{array}{l}51921 \pm \\
2870^{a b}\end{array}$ & $\begin{array}{c}5586 \pm \\
1500^{a b}\end{array}$ \\
\hline Linfócitos & $\begin{array}{l}5919 \pm \\
1744^{a}\end{array}$ & $\begin{array}{l}7103 \pm \\
2687^{a}\end{array}$ & $\begin{array}{l}4651 \pm \\
1894^{b}\end{array}$ & $\begin{array}{c}6276 \pm \\
2450^{a b}\end{array}$ & $\begin{array}{c}6632 \pm \\
1785^{a b}\end{array}$ & $\begin{array}{l}7289 \pm \\
2016^{a}\end{array}$ & $\begin{array}{l}8086 \pm \\
2212^{a}\end{array}$ & $\begin{array}{l}8572 \pm \\
3049^{a}\end{array}$ & $\begin{array}{c}7085 \pm \\
3581^{a b}\end{array}$ & $\begin{array}{l}6004 \pm \\
2132^{a b}\end{array}$ & $\begin{array}{l}7120 \pm \\
1688^{a}\end{array}$ & $\begin{array}{c}6120 \pm \\
2288^{a b}\end{array}$ & $\begin{array}{l}7509 \pm \\
2830^{a}\end{array}$ \\
\hline
\end{tabular}

denciados em alguns momentos são observados na fase aguda de outras infecções bacterianas ou virais, porém, não interferiram no estado geral dos felinos infectados, que permaneceram alertas e dispostos, alimentando-se normalmente. O subtipo e o título viral, a via de inoculação, como também o perfil genético do subgrupo dentro do subtipo podem influenciar a gravidade dos sintomas e a evolução da infecção (Dow et al. 1999, Pedersen et al. 2001, Burkhard et al. 2002, Sellon \& Hartmann 2006).

A alteração clínica mais evidente foi a linfadenomegalia que, de início era discreta e limitada aos linfonodos da região cervical, ao fim da décima segunda semana envolvia os outros linfonodos periféricos e também os abdominais. A hepatoesplenomegalia reflete o comprometimento do tecido monocítico-macrofágico (Brown et al. 1991), como ocorre em outras infecções em que linfócitos e monócitos/macrófagos são envolvidos (Troth et al. 2008). Segundo Callanan et al. (1993), a linfoadenopatia observada na fase aguda da infecção pelo FIV é caracterizada ao exame histopatológico por hiperplasia folicular, seguida de resposta humoral representada pelo surgimento de plasmócitos nos folículos linfoides e no parênquima extrafolicular e ativação do centro germinativo. A hiperplasia linfoide pode ter resultado no aumento gradativo de linfócitos no sangue periférico, embora sem significância estatística, observada entre a quarta e a oitava semana p.i., fato não observado por Sparkes et al. (1993), Linenberger et al. (1995) e Pedersen et al. (2001) que relataram linfopenia predominante na fase aguda da infecção pelo FIV. A soroconversão ocorre nessa ocasião. De acordo com Rimmelzwaan et al. (1994) os gatos infectados permanecem reagentes por toda a vida, sem, no entanto, serem capazes de eliminar a infecção. O estímulo constante do sistema monocítico macrofágico devido à presença do vírus, gradativamente resulta em exaustão e involução folicular, que ocorre cerca de 12 meses p.i. (Brown et al. 1991, Callanan et al. 1993). A linfopenia periférica, a gradativa diminuição de linfócitos CD4 e a inversão da relação CD4/CD8 se tornam evidentes (Torten et al. 1991, Dean et al. 1996), como também a alteração na produção de citocinas que podem influenciar o microambiente medular, linfoide e tímico (Linenberger \& Deng 1999, Tompkins \& Tompkins 2008).

Em um estudo publicado por Hanson et al. (2001), cuja amostra contemplava 101 felinos com doenças esplênicas, as anormalidades detectadas foram linfoma, mastocitoma, hematopoiese extra-medular e/ou hiperplasia linfoide, doença mieloproliferativa, piogranuloma, leucemia eritrocitária, síndrome eosinofílica e esplenite granulomatosa. Não houve nenhuma menção à infecção pelo FIV. Com os dados des- te trabalho a infecção por este retrovírus deve ser incluída dentre as causas de esplenomegalia.

As complicações mais frequentes da síndrome de imunodeficiência adquirida, causada pelo FIV são representadas por quadros de enterite, dermatite, gengivite/estomatite e doença respiratória crônica (Sellon \& Hartmann 2006). A uveíte, de pouca gravidade, observada em um animal indica também o caráter sistêmico da infecção. De acordo com English et al. (1990) e Loesenbeck et al. (1995), as lesões oculares podem ocorrer como consequência direta da infecção viral ou pela resposta imune do hospedeiro.

A pouca intensidade de sintomas na fase inicial da infecção pelo FIV, exceto pela linfadenomegalia generalizada e a hepato-esplenomegalia progressivas, refletindo hiperplasia linfoide, torna difícil, se não impossível, o diagnóstico precoce da infecção dos felinos pelo FIV. O diagnóstico é estabelecido somente quando, meses a anos após a infecção, o paciente felino apresenta-se com a síndrome de imunodeficiência. Nesse intervalo, o gato infectado permanece como fonte de infecção para os gatos suscetíveis, principalmente por terem livre acesso ao ambiente externo, o que possibilita contato com outros animais. Portanto, explica-se a crescente incidência da infecção entre gatos em trabalhos internacionais (Levy et al., 2006) e nacionais (Reche Jr et al. 1997, Souza et al. 2002). Assim, no intuito de estabelecer mais precocemente o diagnóstico da infecção, conclui-se pela necessidade de se pesquisar a infecção pelo FIV em todos os gatos que se apresentarem com estas alterações ou que tenham condições de criação que permitam exposição ao agente, o que permitirá o diagnóstico mais precoce da infecção e a adoção de medidas profiláticas no sentido de minimizar a propagação da infecção.

\section{REFERÊNCIAS}

Beebe A.M., Dua N., Faith T.G., Moore P.F., Pedersen N.C. \& Dandekar S. 1994. Primary stage of feline immunodeficiency virus infection: Viral dissemination and cellular targets. J. Virol. 68:3080-3091.

Brown P.J., Hopper C.D. \& Harbour D.A. 1991. Pathological features of lymphoid tissues in cats with natural feline immunodeficiency virus infection. J. Comp. Pathol. 104:345-355.

Burkhard M.J., Mathiason C.K., O'Halloran K. \& Hoover E.A. 2002. Kinetics of early FIV infection in cats exposed via the vaginal versus intravenous route. AIDS Research and Human Retroviruses 18:217226.

Callanan J.J., Racz P. \& Thompson H. 1993. Morphologic characterization of the lymph node changes in feline immunodeficiency virus infection as an animal model of AIDS, p.115-136. In: Racz P., Letvin N.L. \& Gluckman J.C. (Eds), Animal Models of HIV and other Retroviral Infections. Karger, Basel. 
Dean G.A., Reubel G.H., Moore P.F. \& Pedersen N.C. 1996. Proviral burden and infection kinetics of feline imunodeficiency virus in lymphocyte subsets of blood and lymph node. J. Virology 70:51655169.

Diehl L.J., Mathiason-Dubard C.K., O'Neil L.L., Obert L.A. \& Hoover E.A. 1995. Induction of accelerated feline immunodeficiency virus disease by acute-phase virus passage. J. Virology 69:6149-6157.

Dow S.W., Mathiason C.K. \& Hoover E.A. 1999. In vivo monocyte tropism of pathogenic feline immunodeficiency viruses. J. Virology 73:6852-6861.

English R.V., Nelson P., Johnson C.M., Nasisse M., Tompkins W.A. \& Tompkins M.B. 1994. Development of clinical disease in cats experimentally infected with feline immunodeficiency virus. J. Infect. Dis. 170:543-552.

English R.V., Davidson M.G., Nasisse M.P., Jamieson V.E. \& Lappin M.R. 1990. Intraocular disease associated with feline immunodeficiency virus infection in cats. J. Am. Vet. Med. Assoc. 196:11161119.

Hanson J.A., Papageorges M., Girard E., Menard M. \& Hebert P. 2001. Ultrasonographic appearance of splenic disease in 101 cats. Vet. Radiol. Ultrasound 42:441-445.

Hohdatsu T., Motokama K., Usami M., Amioka M., Okada S. \& Koyama H. 1998. Genetic subtyping and epidemiological study of feline immunodeficiency virus by nested polymerase chain reaction-restriction fragment length polymorphism analysis of the gag gene. J. Virol. Methods 70:107-111.

Lara V.M., Taniwaki S.A. \& Araujo Jr J.P. 2007. Caracterização filogenética de amostras do vírus da imunodeficiência felina (FIV) do Estado de São Paulo. Pesq. Vet. Bras. 27:467-470.

Levy J.K., Scott H.M., Lachtara J.L. \& Crawford P.C. 2006. Seroprevalence of feline leukemia virus and feline immunodeficiency virus infection among cats in North America and risk factors for seropositivity. J. Am. Vet. Med. Assoc. 228:371-376.

Linenberger M.L., Beebe A.M., Pedersen N.C., Abkowitz J.L. \& Dandekar S. 1995. Marrow acessory cell infection and alterations in hematopoiesis accompany severe neutropenia during experimental acute infections with feline immunodeficiency virus. Blood 85:941-951.

Linenberger M.L. \& Deng T. 1999. The effects of feline retroviruses on cytokine expression. Vet. Immunol. Immunopathol. 72:343-368.

Loesenbeck G., Drommer W. \& Heider H.J. 1995. Findings in the eyes of serologically FIV (feline immunodeficiency virus) positive cats. Dtsch. Tierärztl. Wochenschr. 102:348-351.

Matsumura S., Ishida T., Washizu T., Tomoda I., Nagata S., Chiba J. \& Kurata T. 1993. Pathologic features of acquired immunodeficiencylike syndrome in cats experimentally infected with feline immunodeficiency virus. J. Vet. Med. Sci. 55:387-394.

Moraillon A., Barré-Sinoussi F., Parodi A., Moraillon R. \& Dauguet C.
1992. In vitro properties and experimental pathogenic effect of three strains of feline immunodeficiency viruses (FIV) isolated from cats with terminal disease. Vet. Microbiol. 31:41-54.

Nasisse M.P., Guy J.S., Stevens J.B., English R.V. \& Davidson M. G. 1993. Clinical and laboratory findings in chronic conjunctivitis in cats: 91 cases (1983-1991). J. Am. Vet. Med. Assoc. 203:834837.

Phillips T.R., Prospero-Garcia O., Wheeler D.W., Wagaman P.C., Lerner D.L., Fox H.S., Whalen L.R., Bloom F.E., Elder J.H. \& Henriksen S.J. 1996. Neurologic dysfunctions caused by a molecular clone of feline immunodeficiency virus, FIV-PPR. J. Neurology 2:388-396.

Pedersen N.C., Ho E., Brown M.L. \& Yamamoto J.K. 1987. Isolation of a T-lymphotropic virus from domestic cats with an immunodeficiencylike syndrome. Science 235:790-793.

Pedersen N.C., Leutenegger C.M., Woo J. \& Higgins J. 2001. Virulence differences between two field isolates of feline immunodeficiency virus (FIV-A Petaluma and FIV-C Pgammas) in young adult specific pathogen free cats. Vet. Immunol. Immunopathol. 79:53-67.

Reche Jr A., Hagiwara M.K. \& Lucas S.R.R. 1997. Clinical study of acquired immunodeficiency syndrome in domestic cats in São Paulo. Braz. J. Vet. Res. Anim. Sci. 34:152-155.

Rimmelzwaan G.F., Siebelink K.H.J., Broos H., Drost G.A., Weijer K., Van Herwijnem R. \& Osterhaus A.D. 1994. Gag- and env-specific serum antibodies in cats after natural and experimental infection with feline immunodeficiency virus. Vet. Microbiol. 39:53-165.

Sellon R.K. \& Hartmann K. 2006. Feline immunodeficiency virus infection, p.131-143. In: Greene C.E. (Ed.), Infectious Diseases of the Dog and Cat. $3^{\text {rd }}$ ed. Saunders Elsevier, St Louis.

Souza H.J.M., Teixeira C.H.R. \& Graça R.F.S. 2002. Estudo epidemiológico de infecções pelo vírus da leucemia e/ou imunodeficiência felina, em gatos domésticos do município do Rio de Janeiro. Clínica Vet. 36:14-21.

Sparkes A.H., Hooper C.D., Millard W.G., Gruffydd-Jones T.J. \& Harbour D.A. 1993. Feline immunodeficiency virus infection: Clinicopathologic findings in 90 naturally occuring cases. J. Vet. Intern. Med. 7:85-90.

Tompkins M.B. \& Tompkins W.A. 2008. Lentivirus-induced immune dysregulation. Vet. Immunol. Immunopathol. 123:45-55.

Torten M., Franchini M., Barlough J.E., George J.W., Mozes E., Lutz H. \& Pedersen N.C. 1991. Progressive immune dysfunction in cats experimentally infected with feline immunodeficiency virus. J. Virol. 65:2225-2230.

Troth S.P., Dean A.D. \& Hoover E.A. 2008. In vivo CXCR4 expression, lymphoid cell phenotype, and feline immunodeficiency virus infection. Vet. Immunol. Immunopathol. 123:97-105.

Willis A.M. 2000. Feline leukemia virus and feline immundeficiency virus. Vet. Clin. North Am., Small Anim. Pract. 30:971-986 